The FASEB Journal express article 10.1096/fj.03-0032fje. Published online September 4, 2003.

\title{
Heme oxygenase-1 related carbon monoxide production and ventricular fibrillation in isolated ischemic/reperfused mouse myocardium
}

Istvan Bak, ${ }^{1}$ Levente Szendrei, ${ }^{1}$ Tibor Turoczi, ${ }^{2}$ Gabor Papp, ${ }^{1}$ Ferenc Joo, ${ }^{1}$ Dipak K. Das, ${ }^{2}$ Joel de Leiris, ${ }^{3}$ Peter Der, ${ }^{1}$ Bela Juhasz, ${ }^{1}$ Edit Varga, ${ }^{1}$ Ildiko Bacskay, ${ }^{1}$ Jozsef Balla, ${ }^{1}$ Peter Kovacs, ${ }^{1}$ and Arpad Tosaki ${ }^{1}$

${ }^{1}$ Department of Pharmacology and $1^{\text {st }}$ Department of Internal Medicine, Health and Science Center, and Department of Physical Chemistry and Research Group of Homogeneous Catalysis of Hungarian Academy of Sciences, University of Debrecen, Debrecen, Hungary ; ${ }^{2}$ University of Connecticut Health Center, School of Medicine, Farmington, Connecticut, USA; and ${ }^{3}$ University of Joseph Fourier, Department of Cardiovascular Pharmacology, Grenoble, France

Corresponding author: Arpad Tosaki, Dept. Pharmacology, Health and Science Center Univ., Debrecen Nagyerdei krt. 98 4032-Debrecen, Hungary. E-mail: tosaki@king.pharmacol.dote.hu

\section{ABSTRACT}

Heme oxygenase-1 (HO-1)-dependent carbon monoxide $(\mathrm{CO})$ production related to reperfusioninduced ventricular fibrillation (VF) was studied in HO-1 wild-type $(+/+)$, heterozygous $(+/-)$, and homozygous (-/-) isolated ischemic/reperfused mouse heart. In HO-1 homozygous myocardium, under aerobic conditions, HO-1 enzyme activity, HO-1 mRNA, and protein expression were not detected in comparison with aerobically perfused wild-type and heterozygous myocardium. In wild-type, HO-1 hetero- and homozygous hearts subjected to 20 min ischemia followed by $2 \mathrm{~h}$ of reperfusion, the expression of HO-1 mRNA, protein, and HO-1 enzyme activity was detected in various degrees. A reduction in the expression of HO-1 mRNA, protein, and enzyme activity in fibrillated wild-type and heterozygous myocardium was observed. In reperfused/nonfibrillated wild-type and heterozygous hearts, a reduction in HO-1 mRNA, protein expression, and HO-1 enzyme activity was not observed, indicating that changes in HO-1 mRNA, protein, and enzyme activity could be related to the development of VF. These changes were reflected in the HO-1-related endogenous $\mathrm{CO}$ production measured by gas chromatography. In HO-1 knockout ischemic/reperfused myocardium, all hearts showed VF, and no detection in HO-1 mRNA, protein, and enzyme activity was observed. Thus, interventions that are able to increase endogenous CO may prevent the development of VF.

Key words: heme oxygenase-1 expression • ischemia/reperfusion $\bullet$ HO-1 knockout mouse hearts

I t has been proposed that most cases of sudden cardiac death may result from ischemia and/or reperfusion-induced ventricular fibrillation (VF; 1-3). Interest in the development and pharmacological control of reperfusion-induced VF has been stimulated by the realization that such arrhythmias may occur under a number of pathological and clinical circumstances, including the spontaneous relief of coronary artery spasm (4). There is considerable controversy over the mechanisms responsible for the induction of these arrhythmias, and a number of 
different mechanisms have been suggested (5), but the two major factors proposed and generally accepted to explain reperfusion-induced injury and VF are 1) calcium overload and 2) free radical formation. Examples of oxidative stress-related diseases include reperfusion-induced injury occurring after tissue ischemia or stroke and inflammatory processes, such as arthritis (6). Heme oxygenase (HO) catalyzes the rate-limiting step in the oxidative degradation of heme to biliverdin and carbon monoxide ( $\mathrm{CO}$; ref 7). Three isozymes of $\mathrm{HO}$ have been identified and cloned; $\mathrm{HO}-1$, an inducible form, $\mathrm{HO}-2$, and $\mathrm{HO}-3$ constitutive forms (8). Studies demonstrate that HO-1 is induced in response to various interventions causing oxidative stress, including ultraviolet irradiation, hypoxia, and ischemia $(6,9-12)$.

In previous studies, we observed a reduction in HO-1 mRNA expression, its protein, and enzyme activity in ischemic/reperfused fibrillated myocardium but not in nonfibrillated ischemic/reperfused hearts (13). Therefore, in the present study, we decided to approach the question from a different angle using wild-type $(+/+)$, HO-1 heterozygous (+/-), and homozygous (-/-) mouse hearts. The aforementioned findings have led us to speculate that the vulnerability of HO-1 knockout subjects' myocardium to VF may be related to HO-1 mRNA, its protein expression, enzyme activity, and $\mathrm{HO}-1$-related endogenous $\mathrm{CO}$ production. If this were so, we would stress that the absence of HO-1 mRNA and its protein could play a crucial role in the development of reperfusion-induced VF. Our study is concerned with the possibility that reperfusion-induced VF may be initiated by the absence of HO-1 mRNA, its protein, enzyme activity, and $\mathrm{HO}-1$-mediated endogenous $\mathrm{CO}$ production.

Although many mechanisms have been proposed to explain the causes of arrhythmias, relatively little work has been done, to our knowledge, to clarify the mechanism(s) of VF at a gene expression level in ischemic/reperfused myocardium. The long QT disease and idiopathic VF, as known up to now, are the only cardiac disorders based on genetic mutation and cause sudden cardiac death from ventricular arrhythmias (14-16). Thus, our study may offer a further understanding of the arrhythmogenic mechanism(s) at a molecular level and identify the responsibility of $\mathrm{HO}-1$ and $\mathrm{HO}-1$-mediated $\mathrm{CO}$ formation for arrhythmogenesis in ischemic/reperfused hearts.

\section{METHODS}

\section{Animals and heart preparation}

Male mice (25-35 g), wild-type (+/+), heterozygous (+/-), and homozygous mutant (-/-) HO-1 knockout, were used for all studies. Animals received humane care in compliance with the Principles of Laboratory Animal Care formulated by the National Society for Medical Research and the Guide for the Care and Use of Laboratory Animals prepared by the National Academy of Sciences and published by the National Institute of Health (NIH Publication No. 86-23, revised 1985). Mice were anaesthetized with $50 \mathrm{mg} / \mathrm{kg}$ of pentobarbital sodium. After intraperitoneal administration of heparin $(1,000 \mathrm{IU} / \mathrm{kg})$, the chest was opened and the heart was rapidly excised and mounted to a "working" perfusion apparatus described by Hewett et al. (17). The perfusion was established with a modified oxygenated Krebs-Henseleit buffer with the following concentrations (in $\mathrm{mM}$ ): $118.4 \mathrm{NaCl}, 4.1 \mathrm{KCl}, 2.5 \mathrm{CaCl}_{2}, 25 \mathrm{NaHCO}_{3}, 1.17 \mathrm{KH}_{2} \mathrm{PO}_{4}, 1.46$ $\mathrm{MgCl}_{2}$, and 11.1 glucose. The perfusion buffer was previously saturated with a mixture of $95 \%$ $\mathrm{O}_{2}$ and $5 \% \mathrm{CO}_{2}, \mathrm{pH} 7.4$ at $37^{\circ} \mathrm{C}$. To prevent the myocardium from drying out, the heart chamber, 
in which hearts were suspended, was covered and the humidity was kept at a constant level (9095\%).

\section{Registration of VF and measurement of cardiac function}

An epicardial ECG was recorded throughout the experimental period by two silver electrodes attached directly to the heart. The ECGs were analyzed to determine the presence or absence of reperfusion-induced VF. Hearts were considered to be in VF if an irregular undulating baseline was apparent on the ECG. Aortic and coronary flow rates were measured by a timed collection of the aortic and coronary effluents that dripped from the heart. Before ischemia and during reperfusion, heart rate $(\mathrm{HR})$, coronary flow $(\mathrm{CF})$, and aortic flow $(\mathrm{AF})$ rates were registered. Aortic pressure (AOP) and the first derivative of aortic pressure (AOPdp/d $t$ ) were measured by a computer acquisition system.

\section{Determination of infarct size}

Hearts for infarct size measurement were perfused, at the end of each experiment, with $15 \mathrm{ml}$ of $1 \%$ triphenyl tetrazolium (TTC) solution in phosphate buffer $\left(88 \mathrm{mM} \mathrm{Na} \mathrm{HPO}_{4}, 1.8 \mathrm{mM}\right.$ $\mathrm{NaH}_{2} \mathrm{PO}_{4}$ ) via the side arm of the aortic cannula and then stored at $-70^{\circ} \mathrm{C}$ for later analysis. Frozen hearts were sliced transversely (18) in a plane perpendicular to the apico-basal axis into 2-3 mm thick sections, weighted, blotted dry, placed in between microscope slides, and scanned on a Hewlett-Packard Scanjet 5p single pass flat bed scanner (Hewlett-Packard, Palo Alto, CA). With the use of the NIH Image 1.61 image processing software, each digitized image was subjected to equivalent degrees of background subtraction, brightness, and contrast enhancement for improved clarity and distinctness. Infarct zones of each slice were traced, and the respective areas were calculated in terms of pixels (19). The areas were measured by computerized planimetry software, these areas were multiplied by the weight of each slice, and then the results were summed up to obtain the weight of the risk zone (total weight of the left ventricle, mg) and the infarct zone (mg). Infarct size was expressed as the ratio, in percent, of the infarct zone to the risk zone.

\section{Determination of $\mathrm{CO}$ content}

We measured tissue CO content using gas chromatography as described by Cook et al. (20). Briefly, hearts were removed at various time points (before the induction of ischemia and after 5, 15,30 , and $120 \mathrm{~min}$ of reperfusion, respectively) from the perfusion set up and homogenized in 4 volumes of $0.1 \mathrm{M}$ phosphate-buffer (pH: 7.4) using an x520 homogenizer (Ingenieurburo CAT, M. Zipperer GmbH, Staufen, Germany). The homogenates were centrifuged at $4{ }^{\circ} \mathrm{C}$ for 15 min at $12,800 \mathrm{~g}$, and the supernatant fractions were used for the determination of tissue $\mathrm{CO}$. The reaction mixtures contain: $150 \mu \mathrm{l}$ of supernatant, $60 \mu \mathrm{l}$ of NADPH $(4.5 \mathrm{mM})$, and $50 \mu 1$ of $3.5 / 0.35 \mathrm{mM}$ methemalbumin, and for blank samples $60 \mu 1$ phosphate buffer was used instead of NADPH. The samples were preincubated at $37^{\circ} \mathrm{C}$ for $5 \mathrm{~min}$, then the headspace was purged, and the incubation was continued for $1 \mathrm{~h}$ in dark at $37^{\circ} \mathrm{C}$. The reaction was stopped by placing the samples on ice, and the headspace gas was analyzed. One-thousand microliters of the headspace gas from each vial was injected into the gas chromatograph using a gastight syringe (Hamilton Co.) in hydrogen gas flow with a speed of $30 \mathrm{ml} / \mathrm{min}$. Analysis took place during the next $150 \mathrm{~s}$ on a $200 \mathrm{~cm}$ stainless-steel column with a $0.3 \mathrm{~cm}$ inner diameter. The detector was a thermal 
conductivity detector with an AC current of $80 \mathrm{~mA}$. The individual value was expressed in millivolts, and then the area of the peak was integrated and expressed in arbitrary units. The column was packed with Molselect $5 \AA$ and maintained at $30^{\circ} \mathrm{C}$. The temperature of the injector and detector was controlled and kept at $50^{\circ} \mathrm{C}$.

\section{Measurement of cellular $\mathrm{Na}^{+}, \mathrm{K}^{+}$, and $\mathrm{Ca}^{2+}$}

Cellular electrolytes were measured as described previously (21). In brief, hearts were rapidly cooled to $0-5^{\circ} \mathrm{C}$ being submerged and then perfused for 5 min with an ice-cold ion-free buffer solution containing $100 \mathrm{mmol} / \mathrm{l}$ of trishydroxy-methyl-amino-methane and $220 \mathrm{mmol} / \mathrm{l}$ of sucrose to washout ions from the extracellular space and to stop the activity of membrane enzymes responsible for membrane ion transports. Five minutes of cold washing of the heart washes out $>90 \%$ of the ions from the extracellular space (22). After the washout, hearts were dried for $48 \mathrm{~h}$ at $100^{\circ} \mathrm{C}$ and made ash at $550^{\circ} \mathrm{C}$ for $20 \mathrm{~h}$. The ash was dissolved in $5 \mathrm{ml}$ of $3 \mathrm{M}$ nitric acid and diluted 10-fold with deionized water. Myocardial $\mathrm{Na}^{+}$was measured at a wavelength of $330.3 \mathrm{~nm}, \mathrm{~K}^{+}$at $404.4 \mathrm{~nm}$, and $\mathrm{Ca}^{2+}$ at $422.7 \mathrm{~nm}$ in air-acetylene flame using an atomic absorption spectrophotometer (Perkin-Elmer 1100-B). The method for the determination of myocardial ion contents has been described previously $(22,23)$.

\section{Immunohistochemistry}

Paraffin sections $(5 \mu \mathrm{m})$ of left ventricular tissue were incubated in the presence of polyclonal antibody and purified liver HO-1 obtained from rats (Stress Gen Biotech.). Reactions were visualized by immunoperoxidase color reaction in wild-type $(+/+)$, heterozygous $(+/-)$, and homozygous (-/-) HO-1 mutant mice. Formalin fixed tissues were paraffin embedded, and $5 \mu \mathrm{m}$ sections were placed on poly-L-lysine coated glass slides (Sigma, St. Louis, MO). After deparaffinization and rehydration, samples were used for quenching endogenous peroxidases and blocking nonspecific binding sites by $3 \% \mathrm{H}_{2} \mathrm{O}_{2}$ in normal goat serum. Sections were incubated for another $2 \mathrm{~h}$ with $\mathrm{HO}-1$ antibody at a dilution of 1:750 as described in the manufacturer's manual. After being washed in PBS for a few minutes, slides were incubated for additional 30 $\mathrm{min}$ in the presence of purified biotinylated anti/rabbit IgG (Vector) at a dilution of 1:200. Slides were rewashed in PBS and incubated with peroxidase conjugated streptavidin (Zymed) for 30 min followed by red color development using 3-amino-9-ethylcarbazole in $0.1 \mathrm{M}$ of acetate buffer ( $\mathrm{pH}$ 5.2). Sections were counter-stained with Gill's hematoxylin for 15-20 s, rinsed with water, and dipped in 1\% of lithium carbonate. After the water was drained, slides were placed in oven for $30 \mathrm{~min}$ at $80 \mathrm{C}^{\circ}$ and then covered with permount coverslips. Sections were photographed using a Zeis (Germany) light microscope.

\section{Total RNA isolation}

Total RNA was isolated from heart tissue $(100 \mathrm{mg})$ by homogenization in $1 \mathrm{ml}$ of TRIzol reagent (Gibco-BRL, Life Technologies, Eggenstein, Germany), a guanidium thiocianate method (24), as described in the manual. The RNA pellets were dissolved in $100 \mu \mathrm{l}$ diethyl pyrocarbonate water, and the concentrations were calculated from the absorbance at $260 \mathrm{~nm}$ measured by ultraviolet spectroscopy (Beckman DU 640, Beckman Instruments Inc., Fullerton, CA). 


\section{Northern blot}

Thirty micrograms of total RNA were transferred to a nylon membrane according to Sambrook et al. (25), and Northern blot was carried out as described previously by Pataki et al. (13). Purified cDNAs were labeled with $\alpha-\left[{ }^{32} \mathrm{P}\right] \mathrm{dCTP}$ by random hexamer priming. Blots were prehybridized for $2 \mathrm{~h}$ in 50\% formamide, 5x Denhardt's solution, $100 \mu \mathrm{l}$ herring sperm DNA, and $0.5 \%$ SDS, $0.9 \mathrm{M}$ sodium chloride, and $0.09 \mathrm{M}$ sodium citrate at $42^{\circ} \mathrm{C}$. Blots were hybridized with cDNAs, labeled to a specific activity of $3 \times 10^{8} \mathrm{cpm} / \mu \mathrm{g}$ in hybridization fluid at $42^{\circ} \mathrm{C}$ overnight. Hybridized blots were washed in $0.3,0.15$, and $0.015 \mathrm{M}$ sodium chloride; 0.03 , 0.015 , and $0.0015 \mathrm{M}$ sodium citrate, respectively, $\mathrm{pH} 7.0$; and $0.1 \% \mathrm{SDS}$, for $20 \mathrm{~min}$ at $50^{\circ} \mathrm{C}$. Kodak Biomed MR-1 films were exposed for 3-4 days with the use of an intensifying screen and kept at $-80^{\circ} \mathrm{C}$. Blots were washed and reprobed with different cDNAs using the hybridization and washing conditions described above.

\section{Western blot}

Myocardial samples were homogenized in Tris-HCl (13.2 mM/l), glycerol (5.5\%), SDS (0.44\%), and $\beta$-mercaptoethanol. The same amount of soluble protein $(50 \mu \mathrm{g})$ was fractionated by Trisglycine-SDS-polyacrylamide gel (12\%) electrophoresis, and Western blot was carried out as described by Pellacani et al. (26) with the use of an antibody to recombinant rat HO-1 protein.

\section{Experimental time course}

Isolated hearts ( $n=6$ in each group) were aerobically perfused for $30 \mathrm{~min}$ of preischemic period, and during the first 10 min period standard perfusion medium was used in Langendorff mode. During the second 20 min period, isolated Langendorff preparation was switched to "working" mode and control drug-free measurements of electrocardiogram, HR, CF, AF, AOP, AOPdp/d $t$ were recorded. Global ischemia was then induced for $20 \mathrm{~min}$ followed by $2 \mathrm{~h}$ of reperfusion. Because the isolated working heart preparation is more sensitive to various interventions and load-work compared with the "nonworking" Langendorff preparation, the initial 10 min of reperfusion was done in Langendorff mode to try to avoid the development of high incidence of ventricular arrhythmias. If VF was registered during the initial phase of reperfusion, and we needed to register cardiac function, the isolated heart was immediately electrically defibrillated using a single $20 \mathrm{~V}$ square-wave pulse of a $1 \mathrm{~ms}$ duration. Northern and Western blot analysis, infarct size, and myocardial electrolytes were done after $120 \mathrm{~min}$ of reperfusion.

\section{Statistics}

The data for HR, CF, AF, AOP, AOPdp/dt, infarct size, myocardial electrolyte contents, and tissue $\mathrm{CO}$ were expressed as means \pm SE. One-way ANOVA was first carried out to test for any differences between the mean values of all groups. If differences were established, the values of wild-type groups were compared with those of HO-1 heterozygous and homozygous groups by multiple $t$ test followed by Bonferroni correction. A change of $P<0.05$ was considered to be statistically significant. 


\section{RESULTS}

\section{HO-1 knockout mice}

The low HO-1 (-/-) mice survival percentage ( $18 \%)$ was maintained in matings between HO-1 $(+/-)$ and HO-1 (-/-) mice, which yielded $105 \mathrm{HO}-1$ (+/-) and $13 \mathrm{HO}-1$ (-/-) mice; however, matings between HO-1 (-/-) males and HO-1 (-/-) females did not yield viable litters. Thus, we got the necessary numbers of HO-1 (-/-) mice, for the present study, in matings between HO-1 $(+/-)$ and HO-1 (-/-) animals. Mice lacking HO-1 gene were slightly lighter $(26 \pm 3 \mathrm{~g})$ than HO-1 $(+/+)(30 \pm 4 \mathrm{~g})$ or HO-1 (+/-) $(31 \pm 3 \mathrm{~g})$ age-matched littermates from birth to early adulthood (12-13 wk) but were otherwise indistinguishable. However, we observed that, as early as 22 wk of age, most HO-1 (-/-) mice became thin, lost weight, were poorly groomed, and appeared less active than $\mathrm{HO}-1(+/+)$ or HO-1 (+/ $)$ animals. Premature mortalities among HO-1 (-/ -$)$ mice after 22 wk of age were common. Therefore, in our studies, mice 16-18 wk of age were used in all groups.

Figure 1 shows the immunohistochemical localization of HO-1 (upper part) in nonischemic mouse heart. Left ventricular cardiac biopsies were obtained from a wild-type $(+/+)$, a heterozygous (+/-), and a homozygous mutant (-/-) mouse heart, respectively, perfused under aerobic conditions and then subjected to immunochemical reaction as we described in Methods. Homogenous cytoplasmic staining (blue) of HO-1 in wild-type $(+/+)$ nonischemic myocardium was observed after $20 \mathrm{~min}$ of aerobic perfusion (Fig. 1a). Figure $1 b$ shows the same cytoplasmic HO-1 staining (blue) after 20 min of aerobic perfusion in the myocardium obtained from (+/-) mouse heart. In the homozygous (-/-) mutant mouse myocardium, cytoplasmic HO-1 staining was not detected under aerobic perfusion (Fig. 1c, lack of blue staining).

The middle part of Fig. 1 shows the corresponding Northern blot analysis of total mRNA from a wild-type $(+/+)$, a heterozygous $(+/-)$, and a homozygous mutant $(-/-)$ mouse heart. Blots were hybridized with a rat HO-1 cDNA probe recognizing a major mRNA band of $\sim 1.5 \mathrm{~kb}$ in both the $(+/+)$ and $(+/-)$ mouse myocardium, respectively. However, no HO-1 mRNA band was detected in the isolated homozygous mutant $(-/-)$ aerobically perfused mouse heart.

The bottom part of Fig. 1 shows the corresponding Western blot analysis of HO-1 protein expression in wild-type, heterozygous, and homozygous mutant mouse myocardium, respectively. HO-1 protein expression was detected with the use of recombinant rat HO-1

antibody as described in Methods. Data clearly show that neither HO-1 mRNA nor its protein was detected in the homozygous $(-/-)$ myocardium perfused under aerobic conditions.

\section{HO-1 in ischemic/reperfused hearts}

Figure 2 shows immunohistochemical detection of HO-1 enzyme (left and middle panels) and HO-1 protein expression (right panel) in hearts subjected to $20 \mathrm{~min}$ of ischemia followed by 120 min of reperfusion. Upon reperfusion, in wild-type $(+/+)$ control mice (Fig. $2 A)$, HO-1 enzyme localization was detected (blue staining) in nonfibrillated/reperfused myocardium (No-VF). However, in reperfused/fibrillated (VF) wild-type (+/+) myocardium, HO-1 enzyme detection by immunohistochemistry was reduced (less blue area). The same pattern, in HO-1 enzyme 
detection, was obtained in the heterozygous (+/-) nonfibrillated (No-VF) and fibrillated (VF) hearts (Fig. $2 B$ ), indicating that there is no substantial difference between the localization of HO1 enzyme in wild-type $(+/+)$ and heterozygous (+/-) mouse myocardium. Upon reperfusion, because of the absence of HO-1 enzyme in homozygous (-/-) mice, the localization of HO-1 enzyme (the lack of blue area) was not possible in either nonfibrillated or fibrillated homozygous $(-/-)$ myocardium (Fig. 2C). In homozygous (-/-) mouse studies, all hearts developed reperfusion-induced VF; therefore, electric defibrillation (Defib.) was necessary to measure myocardial function during reperfusion.

Figure 2 also shows HO-1 protein expression (right panel) in reperfused/nonfibrillated (No-VF) and fibrillated (VF) wild-type (+/+), HO-1 heterozygous (+/-), and HO-1 homozygous (-/-) mouse myocardium. Thus, corresponding to the immunohistochemical staining (left panel), HO1 protein expression (right panel) was detected in ischemic/reperfused nonfibrillated (No-VF) wild-type (+/+) and nonfibrillated heterozygous (+/-) hearts. However, in HO-1 homozygous hearts (-/-), HO-1 protein was not detected (Fig. 2C) either in ischemic/reperfused nonfibrillated (electrically defibrillated) or fibrillated myocardium. It is important to note that in reperfused/fibrillated wild-type $(+/+)$ mouse heart (Fig. $2 A$ ), a reduction in HO-1 protein expression was observed in comparison with the nonfibrillated myocardium. HO-1 protein detection was not recorded in heterozygous (+/-) fibrillated myocardium (Fig. $2 B)$.

\section{Endogenous CO detection in mouse myocardium}

Figure 3 depicts representative curves of endogenous $\mathrm{CO}$ production detected by gas chromatography in wild-type $(+/+)$, HO-1 heterozygous $(+/-)$, and $\mathrm{HO}-1$ homozygous (-/-) mouse myocardium subjected to $20 \mathrm{~min}$ ischemia followed by 30 and $120 \mathrm{~min}$ of reperfusion. It is shown that in wild-type $(+/+)$ and heterozygous (+/-) hearts subjected to $20 \mathrm{~min}$ of ischemia followed by $30 \mathrm{~min}$ (Fig. $3 b$ and $\underline{c}$ chromatograms) and $120 \mathrm{~min}$ (Fig. $3 d$ and $\underline{e}$ chromatograms) of reperfusion, a substantial increase in $\mathrm{CO}$ production was observed in comparison with the nonischemic wild-type $(+/+$, Fig. $3 a$ chromatogram) myocardium. However, in the homozygous $(-/-)$ mouse myocardium (Fig. $3 f$ and g chromatograms), endogenous $\mathrm{CO}$ production because of the lack of the function of HO-1 system was detected at a low level. The results depicted in Fig. $\underline{3}$ were obtained from wild-type, heterozygous, and homozygous mice that showed no VF upon reperfusion, or hearts were immediately electrically defibrillated if it was necessary. However, in the presence of VF, endogenous CO production was not detected (data not shown).

Figure 4 shows the time course of endogenous CO production in $(+/+)(\underline{A})$ and $(-/-)(\underline{B})$ myocardium subjected to $20 \mathrm{~min}$ of ischemia followed by 5, 15, 30, and $120 \mathrm{~min}$ of reperfusion. The results clearly show that endogenous $\mathrm{CO}$ production was increased in reperfused/nonfibrillated myocardium (hearts were immediately defibrillated if it was necessary). However, a small amount of endogenous $\mathrm{CO}$ production was detected in homozygous (-/-) reperfused/nonfibrillated myocardium (Fig. $4 B$ ), indicating that other pathways may also play some role in endogenous $\mathrm{CO}$ production but that these pathways could be relatively unimportant in comparison with the HO-1-dependent pathway. 


\section{Cardiac function and infarct size}

Before the induction of global ischemia (Table 1), a significant reduction in HR, CF, AF, AOP, and AOPdp/dt was observed in HO-1 knockout homozygous (-/-) mouse hearts in comparison with the corresponding values obtained in wild-type $(+/+)$ and heterozygous $(+/-)$ mouse myocardium. These significant changes, the same trend, in cardiac function were also detected between groups after $20 \mathrm{~min}$ of ischemia followed by $30 \mathrm{~min}$ and $120 \mathrm{~min}$ of reperfusion (Table 1). It is important to note that all hearts developed reperfusion-induced VF in the HO-1 knockout homozygous (-/-) group; therefore, all hearts were electrically defibrillated during reperfusion. Infarct size was significantly increased from $37.6 \pm 4 \%$ (wild type) and $38.5 \pm 4 \%$ (HO-1 heterozygous) to $49.5 \pm 5 \%(P<0.05)$ in the HO-1 homozygous group.

\section{Myocardial $\mathrm{Na}^{+}, \mathrm{K}^{+}$, and $\mathrm{Ca}^{2+}$ contents}

The results (Table 2) show that tissue $\mathrm{Na}^{+}$and $\mathrm{Ca}^{2+}$ contents are significantly elevated before the induction of ischemia in the $(-/-)$ myocardium in comparison with the $(+/+)$ and $(+/-)$ values. In addition, the cellular $\mathrm{K}^{+}$(Table 2$)$ was significantly at a lower level $(253 \pm 8 \mu \mathrm{mol} / \mathrm{g}$ dry weight) in the $(-/-)$ group compared with the nonischemic $(+/+)$ value $(278 \pm 7 \mu \mathrm{mol} / \mathrm{g}$ dry weight). Reperfusion of the ischemic myocardium resulted in a same maldistribution of cellular ion contents in all groups that were further aggravated in the $(-/-)$ myocardium (Table 2$)$.

\section{DISCUSSION}

The sudden onset of severe ischemia in previously healthy or diseased myocardium sets into motion a series of pathological events that continue until the cardiocytes die. Interest in the complications of myocardial ischemia/reperfusion has resulted in much emphasis being placed upon the characterization and treatment of supraventricular and ventricular arrhythmias $(27,28)$. However, the realization that the mechanisms of reperfusion-induced arrhythmias are quite distinct from those associated with the mutation in cardiac ion channel genes and the growing awareness of genetically derived arrhythmias as a clinical encountered event have done much to redress the balance of research interest (29). Interestingly, we have known for a longer period of time that there exists another gaseous molecule, beside nitric oxide (NO), and this is $\mathrm{CO}$, which can be generated endogenously in various tissues. Since the isolation of HO enzyme by Tenhunen et al. (30), in 1968, much of the focus of HO and HO-related CO production has been based on the known fact that $\mathrm{HO}$ enzyme serves as the rate-limiting enzyme in the degradation of heme. In addition, $\mathrm{CO}$ contributes to the regulation of vascular tone and is reported to have antiischemic and immunosuppressive properties, which may contribute to the cytoprotective action of HO-1 in ischemic/reperfused myocardium (12, 31-33). It is of interest to note the findings of Katori et al. (34) and Vulapalli et al. (35) demonstrating that HO-1 overexpression provides protection against ischemia/reperfusion-induced injury in rat hearts, and the protective effect depends on HO-1 modulation of the antiapoptotic pathway. In additional studies, Melo et al. (36) showed that recombinant adeno-associated virus as a vector for direct delivery of the cytoprotective gene HO-1 into the rat heart results in prolonged transgene expression and longterm cardiac protection by reducing the infarct size. We found, in the present study, that infarct size was significantly increased in homozygous $(-/-)$ mouse hearts, and this increase in infarct size related to a significant elevation in myocardial $\mathrm{Na}^{+}$and $\mathrm{Ca}^{2+}$ accumulation and $\mathrm{K}^{+}$loss. We have shown that $\mathrm{HO}-1$ and $\mathrm{HO}-1$-mediated endogenous $\mathrm{CO}$ production play an important role in 
myocardial homeostasis by protecting the heart from ischemia/reperfusion-induced injury, including reperfusion-induced VF. Indeed, after ischemia/reperfusion, there were extensive HO1 mRNA and protein downregulation and enzyme activity reduction in fibrillated HO- 1 heterozygous and homozygous mouse myocardium. The lack of HO-1 mRNA and its protein was observed in aerobically perfused, without an episode of ischemia/reperfusion, homozygous mouse myocardium. Cardiac function in HO-1 knockout homozygous hearts was significantly reduced under aerobic conditions and reperfusion in comparison with the wild-type myocardium. Furthermore, upon reperfusion, all HO-1 knockout homozygous hearts developed reperfusioninduced VF, indicating the importance of the presence of HO-1 mRNA, its protein, and enzyme activity as antiarrhythmic substances in the cardiac tissue. These changes in HO-1 mRNA, protein, and enzyme activity correlated to the HO-1 related endogenous $\mathrm{CO}$ production. Thus, endogenous $\mathrm{CO}$ production was not detected, or at a very low level, in fibrillated HO-1 knockout heterozygous and homozygous myocardium, whereas a substantial presence of endogenous $\mathrm{CO}$ was measured in ischemic/nonfibrillated myocardium.

The precise molecular mechanism(s) by which $\mathrm{HO}-1$ and $\mathrm{HO}-1$ related endogenous $\mathrm{CO}$ production confers myocardial protection is currently under extensive investigation. For instance, bilirubin protects myocardial cells against oxidative damage and improves the recovery of postischemic function in isolated rat hearts (37). Furthermore, elevated serum bilirubin concentrations are associated with reduced risks for the development of early familial coronary artery diseases (38). Thus, it is reasonable to believe that antioxidant effects of bilirubin contribute to cardiac protection, which has a relatively week endogenous defense in comparison with those of other organs such as the liver and intestines (39). It has been recently suggested that $\mathrm{CO}$ could prevent the inflammatory response in hyperoxic injury reducing oxidative damage $(40,41)$. Another well-known pharmacological property of $\mathrm{CO}$ is its vasodilator effect, which could increase the cellular circulation during reperfusion. Thus, it is likely that both the antiinflammatory and vasodilator effects of $\mathrm{CO}$ could contribute to the cardioprotective effect of HO-1 in ischemic/reperfused hearts.

There is a substantial body of evidence supporting the existence of an association in cells between the HO system activity and function that are related to cGMP synthesis. The activation of soluble guanylyl cyclase (sGC) by CO leads to the accumulation of cGMP (42) in cells, indicating a direct relationship between endogenous $\mathrm{CO}$ production and cGMP concentration. Enzymatically derived $\mathrm{CO}$, like nitric monoxide, among other physiological activities, causes relaxation of vascular smooth muscle and inhibits platelet aggregation. Studies have in fact established that, under physiological conditions, maintenance of normal vascular tone and blood flow can be attributed in part to enzymatically derived CO $(43,44)$. Therefore, changes in vascular tone, endothelial permeability, and/or coagulation function observed under hypoxic or ischemic conditions may in part be a consequence of HO-1 induction and localized production of $\mathrm{CO}$.

In the present study, we endeavored to obtain more circumstantial evidence for the involvement of HO-1-related CO production and its direct measurement in the genesis of reperfusion-induced VF in wild-type, heterozygous, and homozygous mice. However, some indication regarding the importance of endogenous $\mathrm{CO}$ production in the regulation of reperfusion-induced VF may be perhaps obtained from our previous studies (13), indicating that downregulation of HO-1 mRNA expression could not be observed in ischemic/reperfused and nonfibrillated myocardium. In a 
previous study (13) we demonstrated that electrically fibrillated myocardium, without the application of an ischemia/reperfusion induced event, resulted in a significant downregulation in HO-1 gene, which could lead to reduced $\mathrm{CO}$ production. This finding was supported in additional studies (45) using zinc-protoporphyrin IX (ZnPPIX), an inhibitor of HO-1 enzyme activity, and N-tert-butyl- $\alpha$-phenylnitrone (PBN) as an inducer of HO-1 mRNA and protein. Thus, ZnPPIX induced the incidence of reperfusion-induced VF and decreased HO-1 signal intensity leading to a reduced amount of endogenous $\mathrm{CO}$ production, whereas PBN significantly increased HO-1 mRNA and protein expression resulting in an increased formation of endogenous $\mathrm{CO}$ production in the rat myocardium. We now provide direct evidence, in the present mouse study, by measuring cellular $\mathrm{CO}$ production by gas chromatography, suggesting that this is the case and the protective effect against the development of reperfusion-induced VF is attributable to the generation of endogenous $\mathrm{CO}$ through HO-1 mRNA induction. Thus, the stimulation of HO-1 mRNA, its protein expression, enzyme activity, and endogenous $\mathrm{CO}$ production demonstrate that endogenous $\mathrm{CO}$ production is essential for the prevention of reperfusion-induced VF. The HO-1 knockout mouse studies strongly suggest the involvement of endogenous $\mathrm{CO}$ production in the mechanism of reperfusion-induced VF.

How can $\mathrm{HO}$ expression provide protection against ischemia/reperfusion-induced injury? Although the main subject of the present study is the delineation of HO-CO system in the ischemic/reperfused myocardium, some discussion of the putative mechanism of action of this pathway must also include some mention of nitric oxide synthase (NOS) system. These two pathway systems show many similarities: both HO and NOS have distinct constitutive and inducible isoforms, and both $\mathrm{CO}$ and NO stimulate soluble guanylyl cyclase to produce cGMP as the second messenger effector. The relative contribution of $\mathrm{CO}$ and NO to the activation of guanylyl cyclase in the cardiovascular system remains unknown, even under physiological conditions. In many pathological conditions such as hypoxia, thermal injury, and ischemia/reperfusion, $\mathrm{CO}$-mediated effects may be predominant. For instance, it was found that an HO-inhibitor blocked cGMP production, whereas a NOS inhibitor had no effect (46). Pannen et al. (47) showed that in a rat model of hemorrhagic shock CO induced sinusoidal dilatation and protection, whereas NO did not appear to play a significant role. However, hyperthermic stress also elevates cGMP via CO but not NO (48). Recent studies have demonstrated that NO is a much more potent stimulator of soluble guanylyl cyclase producing $\sim 300$ - to 400 -fold increase in basal guanylyl cyclase activities in comparison with 5- to 15-fold increase generated by CO (49, 50). It appears likely that, although in general NO is the more dominant activator of guanylyl cyclase, under certain conditions of altered redox state and thermal injury in specific tissues, $\mathrm{CO}$ may be physiologically more important. Because both $\mathrm{NO}$ and $\mathrm{CO}$ mediate their effects through the stimulation of guanylyl cyclase, in future investigation, it is necessary to demonstrate that an increased cardiac cGMP level is at least partly due to $\mathrm{CO}$ rather than NO in our model system.

In summary, we have shown using wild-type, HO-1 knockout heterozygous, and homozygous mice that HO-1 and HO-1-related endogenous $\mathrm{CO}$ production play an important role in the adaptation of cardiovascular system to ischemia followed by reperfusion. The myocardium from HO-1 knockout mice exposed to ischemia/reperfusion was severely injured; the poor recovery of postischemic cardiac function was recorded, and all hearts developed reperfusion-induced VF. On the basis of these findings, we postulate that HO-1 may play a central role in cardiac physiology by protecting the heart from ischemia/reperfusion-induced damage. Our findings suggest that pharmacological stimulation of HO-1 expression could prevent the development of 
reperfusion-induced VF. Thus, it is reasonable to assume that controlled application of exogenous $\mathrm{CO}$, as well as the stimulation of endogenous $\mathrm{CO}$ production, may protect the myocardium as it was stressed in the study of Sato et al. (32) using a model of mouse-to-rat cardiac transplant. In addition, the effects of inhaling (exogenous) $\mathrm{CO}$ were studied by DeBias et al., (51) under in vivo conditions, and the authors found that the voltage required to induce VF (fibrillation threshold) was higher in control monkeys in comparison with infracted animals inhaling CO. This finding could be related with the presence of blood and its elements and their interaction with $\mathrm{CO}$ in their model system. Thus, additional studies are needed to resolve the links in the apparent cascade of the up- and down-regulation of ischemia/reperfusion-induced gene expression and HO enzyme activity in fibrillated and nonfibrillated myocardium.

\section{ACKNOWLEDGMENTS}

This study was supported by the grants from the NATO (LST.CLG.977254), Belgium, ETT (62/2001) and OTKA (T-32008), Hungary, Hungarian-French "TET," and the National Institutes of Health Grants HL-22559 and HL-33889.

\section{REFERENCES}

1. Birnbaum, Y., Kloner, R. A., Sclarovsky, S., Cannon, C. P., McCabe, C. H., Davis, V. G., Zaret, B. L., Wackers, F. J., and Braunwald, E. (1996) Distortion of the terminal portion of the QRS on the admission electrocardiogram in acute myocardial infarction and correlation with infarct size and long-term prognosis (Thrombolysis in myocardial infarction 4 trial). Am. J. Cardiol. 78, 396-403

2. Birnbaum, Y., Hale, S., and Kloner, R. A. (1997) Changes in R wave amplitude: ECG differentiation between episodes of reocclusion and reperfusion associated with ST segment elevation. J. Electrocardiol. 30, 211-216

3. Gray, R. A., Pertsov, A. M., and Jalife, J. (1998) Spatial and temporal organization during cardiac fibrillation. Nature 392, 75-78

4. Tzivoni, D., Keren, A., Granot, H., Gottlieb, S., Benhorin, J., and Stern, S. (1983) Ventricular fibrillation caused by myocardial reperfusion in Prinzmetal's angina. Am. Heart J. 105, 323-325

5. Curtis, M. J., Pugsley, M. K., and Walker, M. J. A. (1993) Endogenous chemical mediators of ventricular arrhythmias in ischemic heart diseases. Cardiovasc. Res. 27, 703-719

6. Maines, M. D. (1997) The heme oxygenase system: a regulator of second messenger gases. Annu. Rev. Pharmacol. Toxicol. 37, 517-554

7. Tyrrell, R. (1999) Redox regulation and oxidant activation of heme oxygenase-1. Free. Rad. Res. 31, 335-340

8. Choi, A. M. K. Heme oxygenase-1 protects the heart. (2001) Circ. Res. 89, 105-107 
9. Lee, P. J., Jiang, B. H., Chin, B. Y., Iyer, N. V., Alam, J., Semenza, G. L., and Choi, A. M. K. (1997) Hypoxia-inducible factor-1 mediates transcriptional activation of the heme oxygenase-1 gene in response to hypoxia. J. Biol. Chem. 272, 5375-5381

10. Otterbein, L. E., Lee, P. J., Chin, B. Y., Petrache, I., Camhi, S. L., Alam, J., and Choi, A. M. (1999) Protective effects of heme oxygenase-1 in acute lung injury. Chest 116, S61-S63

11. Reeve, V. E., and Tyrrell, R. M. (1999) Heme oxygenase induction mediates the photoimmunoprotective activity of UVA radiation in the mouse. Proc. Natl. Acad. Sci. USA 96, 9317-9321

12. Yet, S. F., Tian, R., Layne, M. D., Wang, Z. Y., Maemura, K., Solovyeva, M., Ith, B., Melo, L. G., Zhang, L., Ingwall, J. S., et al. (2001) Cardiac-specific expression of heme oxygenase-1 protects against ischemia and reperfusion injury in transgenic mice. Circ. Res. 89, $168-173$

13. Pataki, T., Bak, I., Csonka, C., Kovacs, P., Varga, E., Blasig, I. E., and Tosaki, A. (2001) Regulation of ventricular fibrillation by heme oxygenase in ischemic/reperfused hearts. Antioxid. Redox Signal. 3, 125-134

14. Keating, M. T., and Sanguinetti, M. C. (1996) Molecular genetic insights into cardiovascular disease. Science 272, 681-685

15. Rosen, M. R. (1995) Long QT syndrome patients with gene mutations. Circulation 92, $3373-3375$

16. Wang, Q., Curran, M. E., Splawski, I., Burn, T. C., Millholland, J. M., VanRaay, T. J., Shen, J., Timothy, K. W., Vincent, G. M., De Jager, T., et al. (1996) Positional cloning of a novel potassium channel gene: KVLQT1 mutations cause cardiac arrhythmias. Nature Gen. 12, $17-23$

17. Hewett, T. E., Grupp, I. L., Grupp, G., and Robinson, J. (1994) $\alpha$-Skeletal actin is associated with increased contractility in the mouse heart. Circ. Res. 74, 740-746

18. Schultz, J. E., Yao, Z., Cavero, I., and Gross, G. J. (1997) Glibenclamide-induced blockade of ischemic preconditioning is time dependent in intact rat heart. Am. J. Physiol. 272, H2607-H2615

19. Dickson, E. W., Blehar, D. J., Carraway, R. E., Heard, S. O., Steinberg, G., and Przyklenk, K. (2001) Naloxone blocks transferred preconditioning in isolated rabbit hearts. J. Mol. Cell. Cardiol. 33, 1751-1756

20. Cook, M. N., Nakatsu, K., Marks, G. S., McLaughlin, B. E., Vreman, H. J., Stevenson, D. K., and Brien, J. F. (1995) Heme oxygenase activity in adult rat aorta and liver as measured by carbon monoxide formation. Can. J. Physiol. Pharmacol. 73, 515-518 
21. Tosaki, A., Balint, S., and Szekeres, L. (1988) Protective effect of lidocaine against ischemia and reperfusion-induced arrhythmias and shifts of myocardial sodium, potassium, and calcium content. J. Cardivasc. Pharmacol. 12, 621-628

22. Pridjian, A. K., Levitsky, S., Krukenkamp, I., Silverman, N. A., and Feinberg, H. (1987) Developmental changes in reperfusion injury: a comparison of intracellular cation accumulation in the newborn, neonatal, and adult heart. J. Thorac. Cardiovasc. Surg. 93, $428-433$

23. Alto, L. E., and Dhalla, N. S. (1979) Myocardial cation contents during induction of calcium paradox. Am. J. Physiol. 23, 713-719

24. Chomczynski, P., and Sacchi, N. (1987) Single-step method of RNA isolation by acid guanidium thiocyanate-phenol-chlorophorm extraction. Anal. Biochem. 162, 156-159

25. Sambrook, J., Fritsch, E. F., and Maniatis, T. (1989) In Molecular cloning: A laboratory manual, $2^{\text {nd }}$ ed., Cold Spring Harbor Laboratory, Cold Spring Harbor, New York

26. Pellacani, A., Wiesel, P., Sharma, A., Foster, L. C., Huggins, G. S., Yet, S. F., and Perrella, M. A. (1998) Induction of heme oxygenase-1 during endotoxemia is downregulated by transforming growth factor-beta 1. Circ. Res. 83, 396-401

27. Kloner, R. A., Przyklenk, K., and Whittaker, P. (1989) Deleterious effects of oxygen radicals in ischemia/reperfusion. Resolved and unresolved issues. Circulation 80, 11151127

28. Li, Y., and Kloner, R. A. (1995) Is there a gender difference in infarct size and arrhythmias following experimental coronary occlusion and reperfusion? J. Thromb. Thrombolysis 2, $221-225$

29. Simkovich, B. Z., Abdishoo, S., Poizat, C., Hale, S. L., Kedes, L. H., and Kloner, R. A. (2002) Gene activity changes in ischemically preconditioned rabbit heart gene: discovery array study. Heart Dis. 4, 63-69

30. Tenhunen, R., Marver, H. S., and Schmid, R. (1968) The enzymatic conversation of heme to bilirubin by microsomal heme oxygenase. Proc. Natl. Acad. Sci. USA 61, 748-755

31. Yet, S. F., Perrella, M. A., Layne, M. D., Hsieh, C. M., Maemura, K., Kobzik, L., Wiesel, P., Christou, H., Kourembanas, S., and Lee, M. E. (1999) Hypoxia induces severe right ventricular dilatation and infarction in heme oxygenase-1 null mice. J. Clin. Invest. 103, R23-R29

32. Sato, K., Balla, J., Otterbein, L., Smith, R. N., Brouard, S., Lin, Y., Csizmadia, E., Sevigny, J., Robson, S. C., Vercellotti, G., et al. (2001) Carbon monoxide generated by heme oxygenase 1 suppresses the rejection of mouse-to-rat cardiac transplants. J. Immunol. 166, 4185-4194 
33. Lakkisto, P., Palojoki, E., Backlund, T., Saraste, A., Tikkanen, I., Voipio-Pulkki, L. M., and Pulkki, K. (2002) Expression of heme oxygenase-1 in response to myocardial infarction in rats. J. Mol. Cell. Cardiol. 34, 1357-1365

34. Katori, M., Buelow, R., Ke, B., Ma, J., Coito, A. J., Iyer, S., Southard, D., Busuttil, R. W., and Kupiec-Weglinski, J. W. (2002) Heme oxygenase-1 overexpression protects rat hearts from cold ischemia/reperfusion injury via an antiapoptotic pathway. Transplantation 73, 287-292

35. Vulapalli, S. R., Chen, Z., Chua, B. H., Wang, T., and Liang, C. S. (2002) Cardioselective overexpression of HO-1 prevents I/R-induced cardiac dysfunction and apoptosis. Am. J. Physiol. 283, H688-H694

36. Melo, L. G., Agrawal, R., Zhang, L., Rezvani, M., Mangi, A. A., Ehsan, A., Griese, D. P., Dell'Acqua, G., Mann, M. J., Oyama, J., et al. (2002) Gene therapy strategy for long-term myocardial protection using adeno-associated virus-mediated delivery of heme oxygenase gene. Circulation 105, 602-607

37. Clark, J. E., Foresti, R., Sarathchandra, P., Kaur, H., Green, C. J., and Motterlini, R. (2000) Heme oxygenase-1-derived bilirubin ameliorates postischemic myocardial disfunction. $\mathrm{Am}$. J. Physiol. 278, H643-H651

38. Hopkins, P. N., Wu, L. L., Hunt, S. C., James, B. C., Vincent, G. M., and Williams, R. R. (1996) Higher serum bilirubin is associated with decreased risk for early familial coronary artery disease. Arterioscler. Thromb. Vasc. Biol. 16, 250-255

39. Doroshow, J. H., Locker, G. Y., and Myers, C. E. (1980) Enzymatic defenses of the mouse heart against reactive metabolites: alterations produced by doxorubicin. J. Clin. Invest. 65, $128-135$

40. Otterbein, L. E., Mantell, L. L., and Choi, A. M. (1999) Carbon monoxide provides protection against hyperoxic lung injury. Am. J. Physiol. 276, L688-L694

41. Otterbein, L. E., Bach, F. H., Alam, J., Soares, M., Tao, L. H., Wysk, M., Davis, R. J., Flavell, R. A., and Choi, A. M. (2000) Carbon monoxide has anti-inflammatory effects involving the mitogen-activated protein kinase pathway. Nat. Med. 6, 422-428

42. Ingi, T., Cheng, J., and Ronnett, G. V. (1996) Carbon monoxide: an endogenous modulator of the nitric oxide-cyclic GMP signaling system. Neuron 16, 835-842

43. Christodoulides, N., Durante, W., Kroll, M. H., and Schafer, A. I. (1995) Vascular smooth muscle cell heme oxygenases generate guanylyl cyclase-stimulatory carbon monoxide. Circulation 91, 2306-2309

44. Suematsu, M., Goda, N., Sano, T., Kashiwagi, S., Egawa, T., Shinoda, Y., and Ishimura, Y. (1995) Carbon monoxide: an endogenous modulator of sinusoidal tone in the perfused rat liver. J. Clin. Invest. 96, 2431-2437 
45. Bak, I., Papp, G., Turoczi, T., Varga, E., Szendrei, L., Vecsernyes, M., Joo, F., and Tosaki, A. (2002) The role of heme oxygenase-related carbon monoxide and ventricular fibrillation in ischemic/reperfused hearts. Free. Rad. Biol. Med. 33, 639-648

46. Morita, T., Perrella, M. A., Lee, M., and Kourembanas, S. (1995) Smooth muscle cellderived carbon monoxide is a regulator of vascular cGMP. Proc. Natl. Acad. Sci. USA 92, $1475-1479$

47. Pannen, B. H., Kohler, N., Hole, B., Bauer, M., Clemens, M. G., and Geiger, K. K. (1998) Protective role of endogenous carbon monoxide in hepatic microcirculatory dysfunction after hemorrhagic shock in rats. J. Clin. Invest. 102, 1220-1228

48. Ewing, J. F., Raju, V. S., and Maines, M. D. (1994) Induction of heart heme oxygenase-1 (HSP32) by hyperthermia: possible role in stress-mediated elevation of cyclic 3',5'guanosine monophosphate. J. Pharmacol. Exp. Ther. 271, 408-414

49. Hoenicka, M., Becker, E. M., Apeler, H., Sirichoke, T., Schroder, H., Gerzer, R., and Stasch, J. P. (1999) Purified soluble guanylyl cyclase expressed in a baculovirus/sf9 system: stimulation by YC-1, nitric oxide, and carbon monoxide. J. Mol. Med. 77, 14-23

50. Sharma, V. S., and Magde, D. (1999) Activation of soluble guanylate cyclase by carbon monoxide and nitric oxide: a mechanistic model. Methods 19, 495-505

51. DeBias, D. A., Banerjee, C. M., Birkhead, N. C., Greene, C. H., Scott, S. D., and Harrer, W. V. (1976) Effects of carbon monoxide inahalation on ventricular fibrillation. Arch. Environ. Health 31, 38-42 


\section{Table 1}

Effects of $30 \mathrm{~min}$ of ischemia followed by $120 \mathrm{~min}$ of reperfusion on the recovery of cardiac function in wild-type, HO-1 heterozygous, and HO-1 homozygous mice

Before ischemia $\quad$ Reperfusion

$30 \mathrm{~min} \quad 120 \mathrm{~min}$

\begin{tabular}{|c|c|c|c|c|c|c|c|c|c|c|c|c|c|c|c|}
\hline & HR & $\mathrm{CF}$ & $\mathrm{AF}$ & AOP & $\mathrm{AOPdp} / \mathrm{dt}$ & HR & $\mathrm{CF}$ & $\mathrm{AF}$ & AOP & $\begin{array}{c}\text { AOPdp/ } \\
\mathrm{dt}\end{array}$ & HR & $\mathrm{CF}$ & $\mathrm{AF}$ & AOP & $\begin{array}{l}\text { AOPdp/ } \\
\mathrm{dt}\end{array}$ \\
\hline $\begin{array}{l}\text { Wild type } \\
\qquad(+/+)\end{array}$ & $290 \pm 10$ & $2.8 \pm 0.2$ & $3.1 \pm 0.2$ & $161 \pm 7$ & $3876 \pm 76$ & $260 \pm 11$ & $2.1 \pm 0.1$ & $1.0 \pm 0.1$ & $74 \pm 5$ & $990 \pm 40$ & $270 \pm 10$ & $2.2 \pm 0.1$ & $0.8 \pm 0.1$ & $69 \pm 5$ & $964 \pm 55$ \\
\hline $\begin{array}{c}\text { Heterozygous } \\
(+/-)\end{array}$ & $294 \pm 9$ & $2.7 \pm 0.2$ & $3.0 \pm 0.1$ & $152 \pm 8$ & $3924 \pm 90$ & $248 \pm 8$ & $1.9 \pm 0.2$ & $0.9 \pm 0.1$ & $68 \pm 5$ & $935 \pm 38$ & $251 \pm 8$ & $2.0 \pm 0.1$ & $0.7 \pm 0.1$ & $61 \pm 4$ & $893 \pm 37$ \\
\hline $\begin{array}{c}\text { Homozygous } \\
(-/-) \\
\text { defibrillated }\end{array}$ & $252 \pm 7^{*}$ & $2.0 \pm 0.1^{*}$ & $1.7 \pm 0.1^{*}$ & $127 \pm 6^{*}$ & $2851 \pm 57^{*}$ & $224 \pm 7 *$ & $0.8 \pm 0.1 *$ & $0.4 \pm 0.1 *$ & $42 \pm 4 *$ & $641 \pm 32 *$ & $230 \pm 6^{*}$ & $1.1 \pm 0.1 *$ & $0.6 \pm 0.1^{*}$ & $44 \pm 5^{*}$ & $627 \pm 29^{*}$ \\
\hline
\end{tabular}

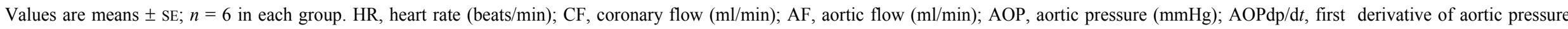
$(\mathrm{mmHg} / \mathrm{s}) .{ }^{*} P<0.05$, comparisons were made to the time-matched control values (wild type). 
Table 2

Cellular $\mathrm{Na}^{+}, \mathrm{K}^{+}$, and $\mathrm{Ca}^{2+}$ contents ( $\mu \mathrm{mol} / \mathrm{g}$ dry weight) before ischemia and after reperfusion in $\mathrm{HO}-1$ wild-type (+/+), heterozygous (+/-), and homozygous (-/-) mouse hearts

\begin{tabular}{|c|c|c|c|c|c|c|}
\hline \multirow[t]{2}{*}{ Group } & \multicolumn{2}{|r|}{ Before } & \multicolumn{2}{|c|}{$A$} & \multicolumn{2}{|c|}{ After 120 min RE } \\
\hline & $\mathrm{Na}^{+}$ & $\mathrm{K}^{+}$ & $\mathrm{Ca}^{2+}$ & $\mathrm{Na}^{+}$ & $\mathrm{K}^{+}$ & $\mathrm{Ca}^{2+}$ \\
\hline$+/+$ & $29 \pm 4$ & $278 \pm 7$ & $1.7 \pm 0.2$ & $80 \pm 6$ & $233 \pm 6$ & $4.3 \pm 0.5$ \\
\hline$+/-$ & $31 \pm 3$ & $270 \pm 9$ & $1.8 \pm 0.3$ & $86 \pm 8$ & $233 \pm 9$ & $4.3 \pm 0.7$ \\
\hline$-/-$ & $39 \pm 4 *$ & $253 \pm 8^{*}$ & $2.6 \pm 0.4 *$ & $99 \pm 7 *$ & $180 \pm 9^{*}$ & $5.5 \pm 0.6^{*}$ \\
\hline
\end{tabular}

Comparisons were made to the wild-type $(+/+)$ values; $n=6$ in each group. $* P<0.05$. ISA, ischemia; RE, reperfusion. 
Fig. 1

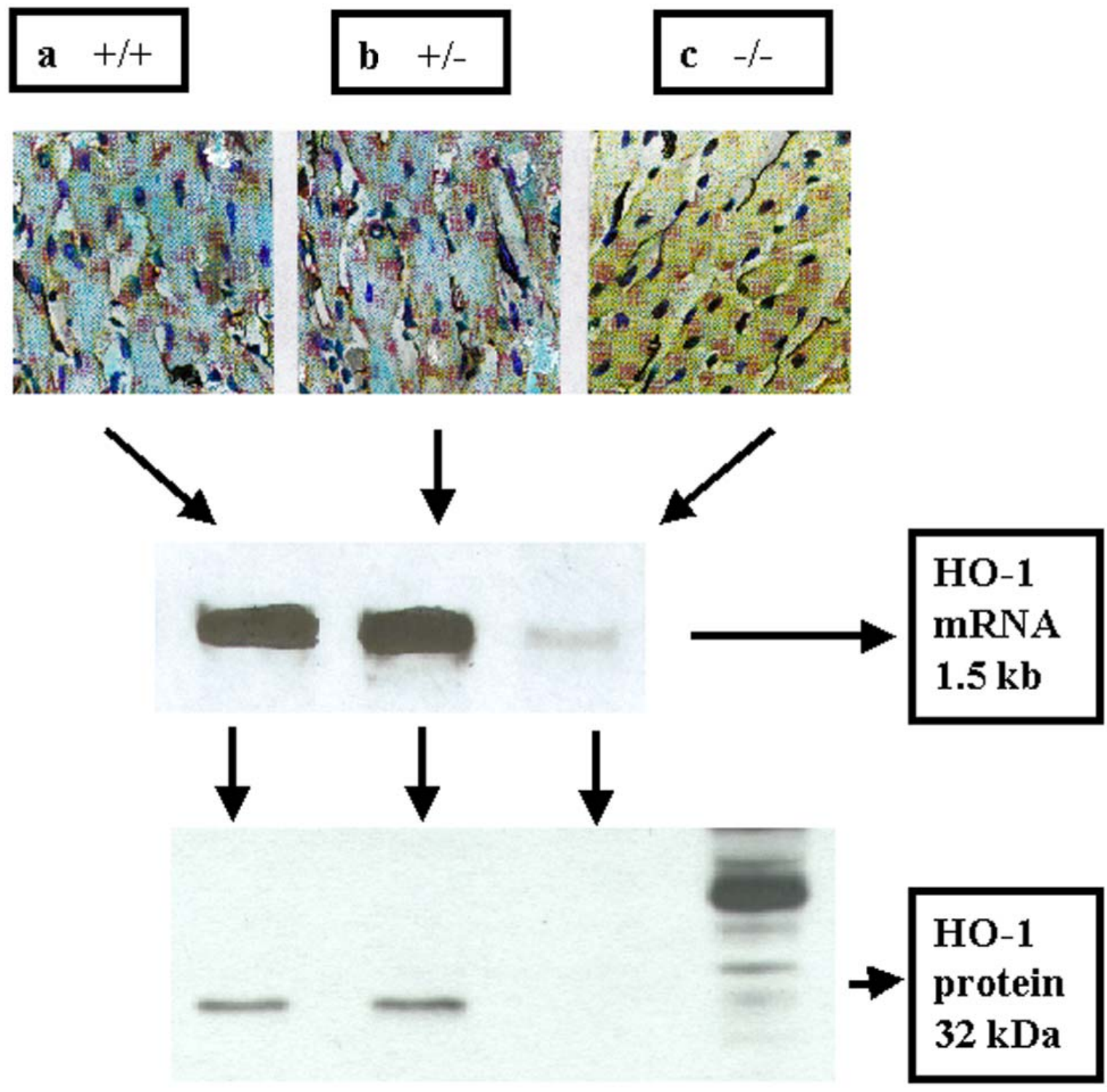

Figure 1. Localization of HO-1 by immunohistochemistry in the mouse heart. A representative picture of left cardiac biopsy obtained from a wild-type (+/+), a heterozygous (+/-), and a homozygous mutant (-/-) mouse heart, respectively, perfused under aerobic conditions. Upper part shows homogenous cytoplasmic staining (blue) of HO-1 in wild-type $(+/+)$ myocardium (a) after 20 min of aerobic perfusion. $\boldsymbol{b}$ ) Same cytoplasmic HO-1 staining (blue) after 20 min aerobic perfusion in the myocardium obtained from heterozygous (+/-) mouse. In the homozygous (-/-) mutant mouse heart (c), cytoplasmic HO-1 staining was not observed after $20 \mathrm{~min}$ of aerobic perfusion. The middle part shows Northern blot analysis of total mRNA from a wild-type $(+/+)$, a heterozygous $(+/-)$, and a homozygous mutant $(-/-)$ mouse heart. Blots were hybridized with a rat HO- $1 \mathrm{cDNA}$ probe recognizing a major mRNA band of $\sim 1.5 \mathrm{~kb}$ in both the $(+/+)$ and $(+/-)$ mouse myocardium, respectively. The lower part shows Western blot analysis of HO-1 protein expression in wild-type, heterozygous, and homozygous mutant mouse heart, respectively. HO-1 protein expression was detected with the use of recombinant rat HO-1 antibody as described in the Methods. 
Fig. 2

\section{HO- 1 immunohistochemistry}

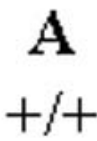

B

$+1-$
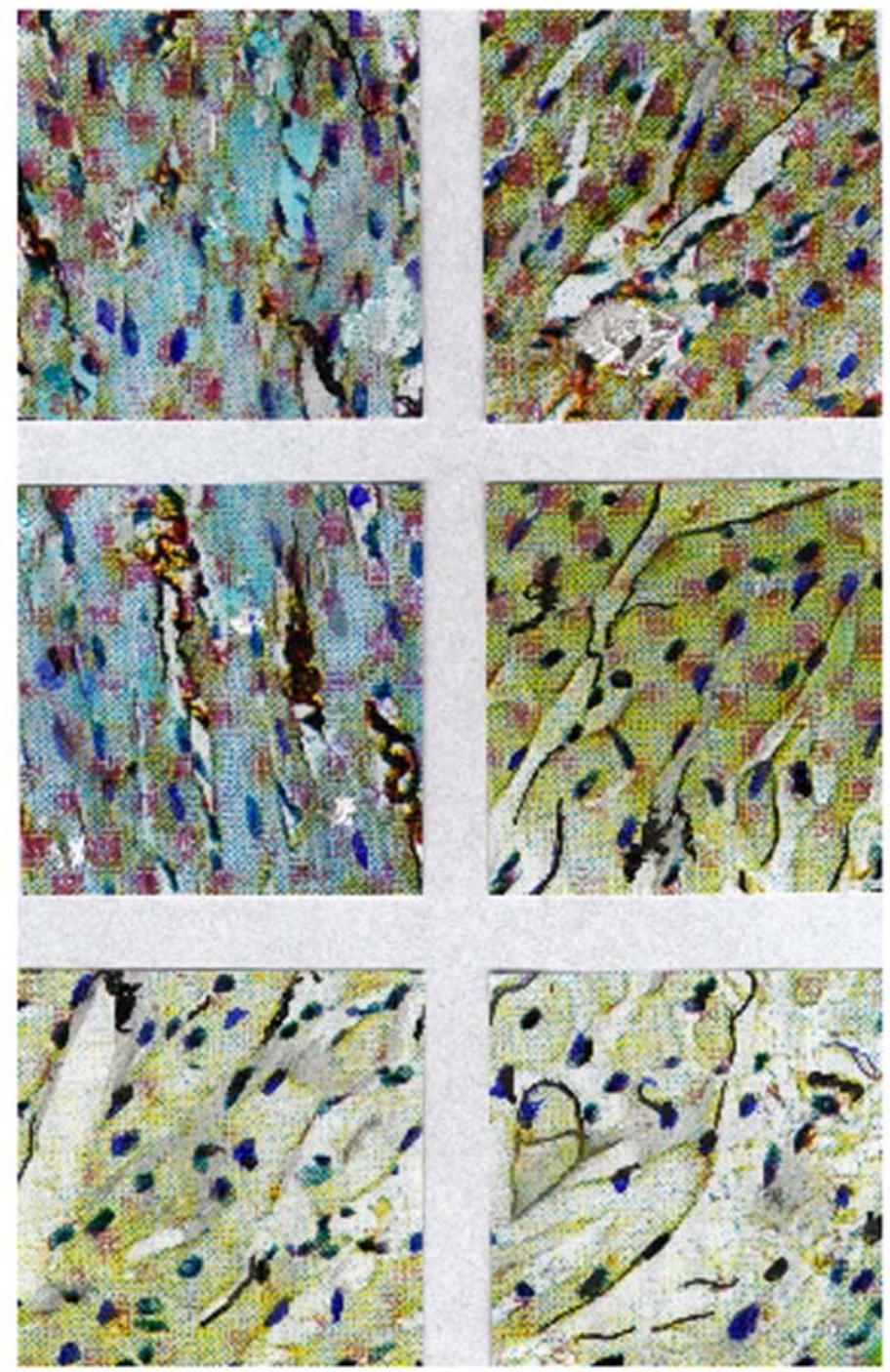

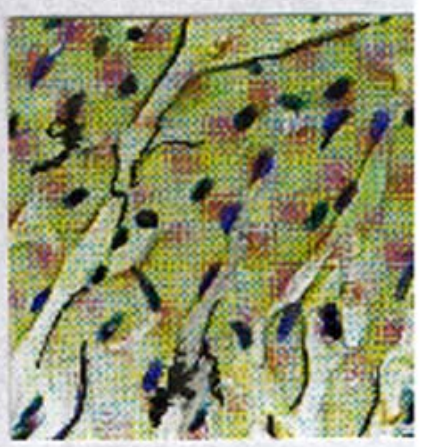

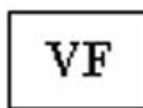

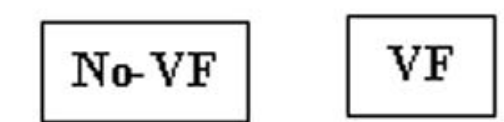

\section{HO-1 protein}
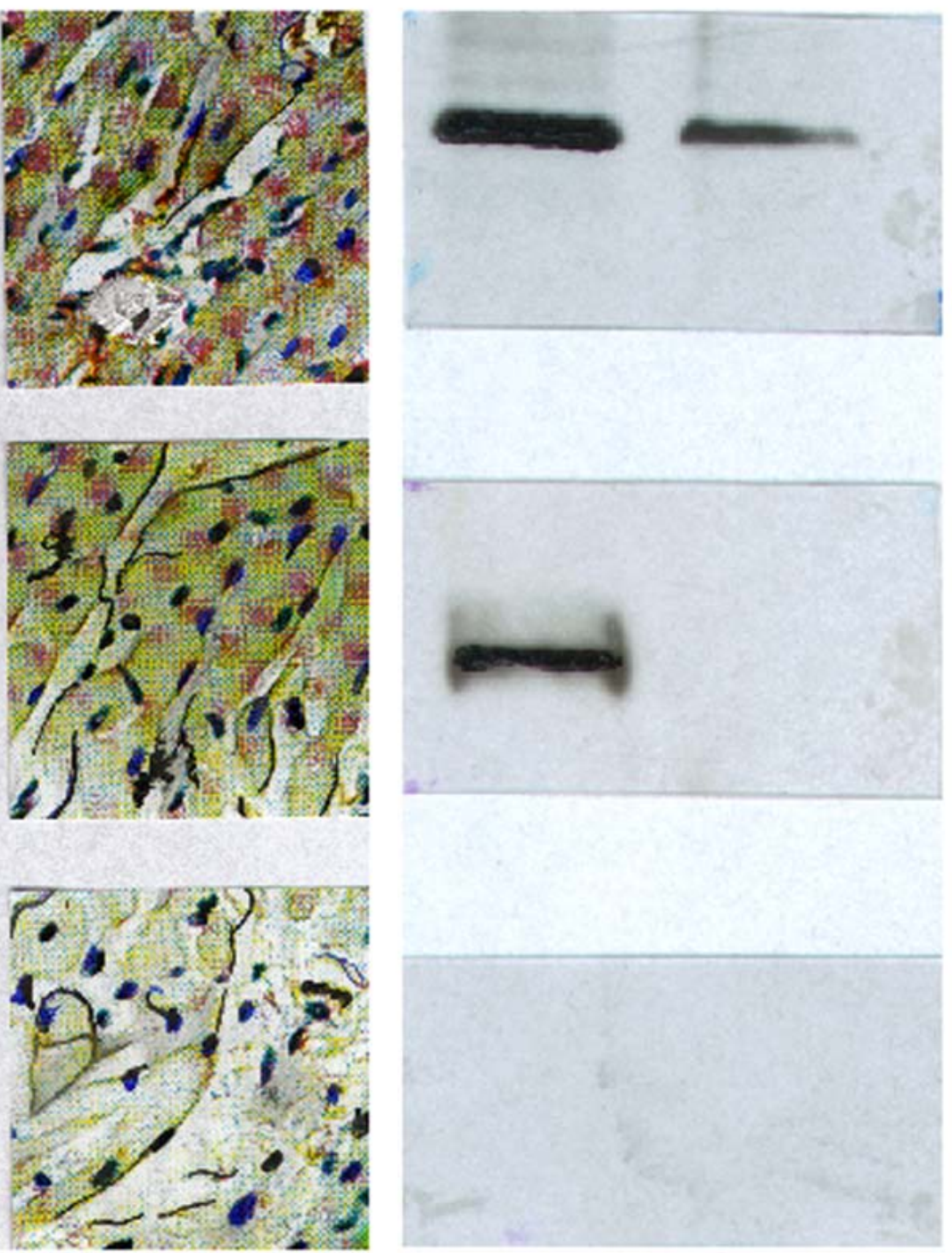

Figure 2. Detection of HO-1 enzyme by immunohistochemistry (left and middle panels) and HO-1 protein expression (right panels) by Western blot in hearts subjected to $20 \mathrm{~min}$ of ischemia followed by $120 \mathrm{~min}$ of reperfusion in wild-type $(+/+; A)$, heterozygous $(+/-; B)$, and homozygous $(-/-; C)$ nonfibrillated (No-VF) and fibrillated (VF) mouse heart. The presence of HO-1 enzyme is shown in blue (left and middle panels), and HO-1 protein expression (right panels) is represented by lanes, in wild-type, heterozygous, and homozygous nonfibrillated or fibrillated myocardium. Because of the lack of HO-1 enzyme, blue cytoplasmic staining cannot be detected either in No-VF or VF homozygous (-/-) myocardium $(\boldsymbol{C})$. All hearts showed VF upon reperfusion in the homozygous group; therefore, all preparations were defibrillated (Defib.). 
Fig. 3

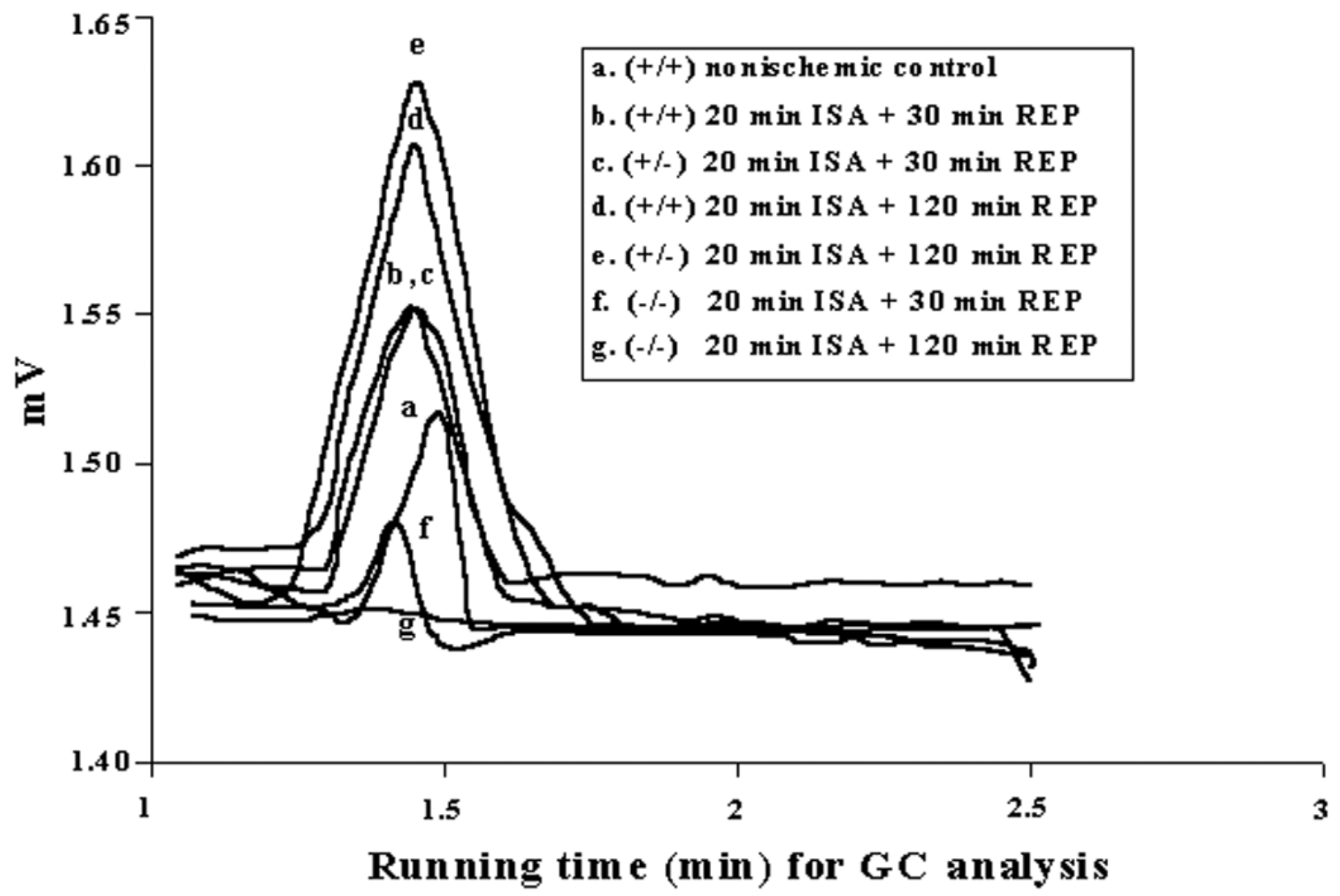

Figure 3. Representative GC chromatograms for the demonstration of endogenous $\mathrm{CO}$ production in wild-type $(+/+)$, heterozygous (+/-), and homozygous (-/-) mouse myocardium subjected to 20 min of ischemia followed by 30 min and 120 min of reperfusion, respectively. It is clearly shown that in homozygous (-I-) mutant hearts $(\boldsymbol{f}$ and $\boldsymbol{g}$ chromatogram), there is very little detectable endogenous $\mathrm{CO}$ production after $20 \mathrm{~min}$ of ischemia followed by $30 \mathrm{~min}$ or 120 min of reperfusion. ISA, ischemia; REP, reperfusions. Note: hearts did not show VF upon reperfusion, or if VF was detected, defibrillation was immediately used. 
Fig. 4
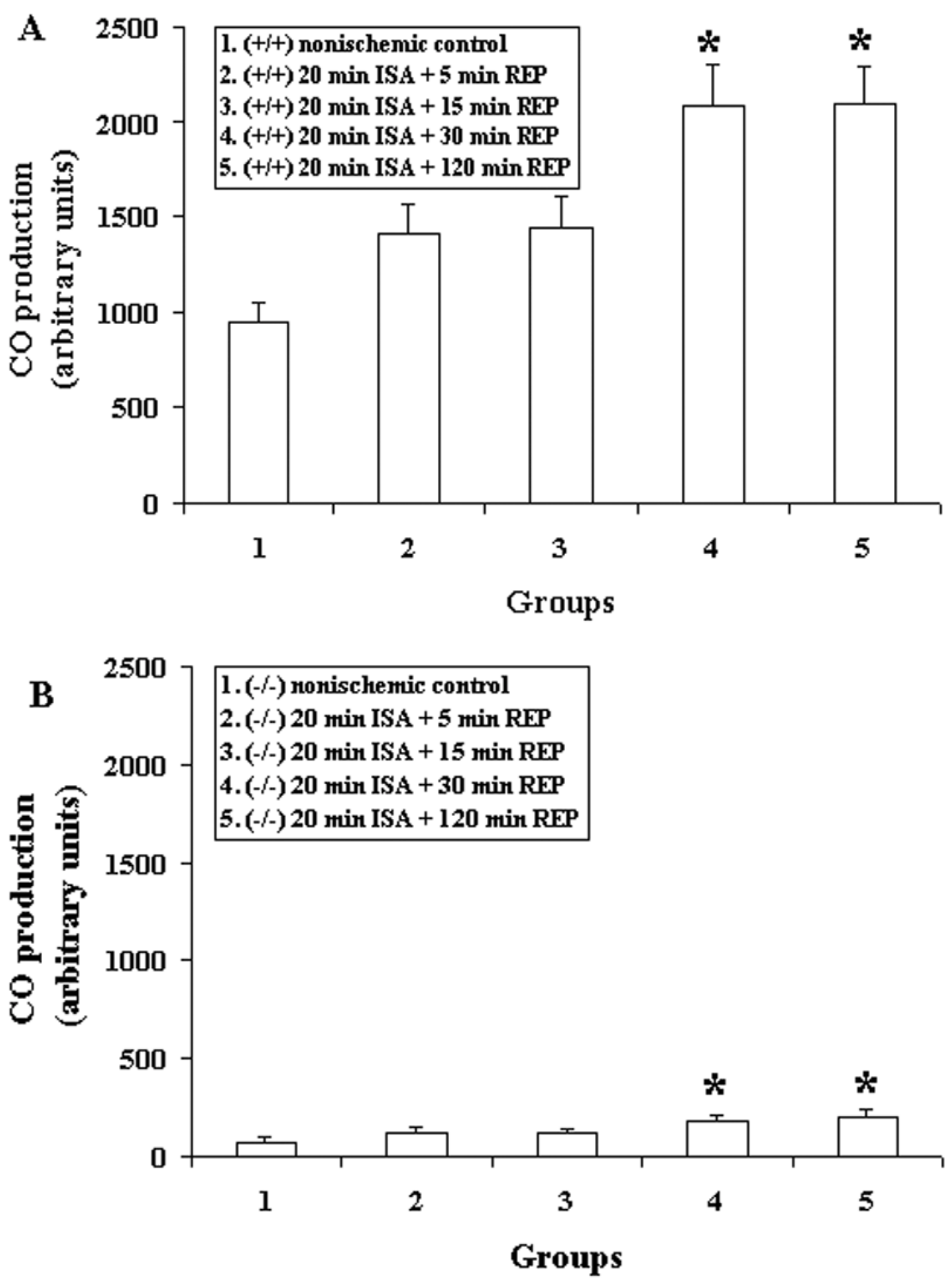

Figure 4. Quantitative and time-course studies for endogenous $\mathrm{CO}$ production in ischemic/reperfused wild-type $(+/+; A)$ and homozygous $(-I-)$ HO-1 knockout $(B)$ hearts. Hearts ( $n=6$ in each group) were isolated and subjected to 20 min of global ischemia followed by $2 \mathrm{~h}$ of reperfusion. Endogenous tissue $\mathrm{CO}$ levels were measured in aerobically perfused myocardium (control) in hearts subjected to $20 \mathrm{~min}$ ischemia followed by 5, 15, 30, and $120 \mathrm{~min}$ of reperfusion, respectively. $* P<0.05$, comparisons were made to the control (group 1) nonischemic myocardium. 